\title{
INCREASED LEFT VENTRICULAR MASS IN A BODYBUILDER USING ANABOLIC STEROIDS
}

\author{
G. MCKILLOP, MB, MRCP* I. C. TODD, MB, MRCP* and D. BALLANTYNE, MD. FRCP(Glas)** \\ ${ }^{*}$ Registrar and **Consultant Physician and Cardiologist, Department of Medical Cardiology, Victoria Infirmary, Glasgow
}

\section{ABSTRACT}

As the effects of anabolic steroids on left ventricular structure and function are unknown, we carried out clinical examination, 12 lead electrocardiography and echocardiography on a 23 year old male bodybuilder using these drugs.

In this subject we found values of ECG voltage criteria, left ventricular-mass, posterior wall and interventricular septal thickness which exceeded those found in normal subjects and also in other competitive, power athletes. Despite these values, however, ejection fraction remained normal.

This would suggest that anabolic steroids perhaps have a direct effect on the myocardium, in addition to the effects of training, but whether this is of pathological significance is unclear.

Key Words: Anabolic steroids, Body builders, Ventricular mass

\section{INTRODUCTION}

Anabolic steroids are used by athletes in an attempt to increase skeletal muscle hypertrophy and strength. The effect of these drugs on cardiac muscle is unknown. We report a case of marked left ventricular hypertrophy on electrocardiographic and echocardiographic criteria, in a bodybuilder using anabolic steroids.

\section{CASE REPORT}

A 23 year old male bodybuilder who had been training continually for 10 years underwent clinical examination and had a standard 12 lead electrocardiograph (ECG) and a 2-D and M-mode echocardiograph (Hewlett Packard Phased Array $90^{\circ}$ Sector Scanner), performed. He had been using anabolic steroids intermittently for 8 years. When tested he had been taking anabolic steroids (Nandrolone Decanoate $100 \mathrm{mg}$ intramuscularly once weekly and Stanozolol $30 \mathrm{mg}$ orally daily) for $\mathbf{8}$ weeks, after a four week drug-free interval. His normal training schedule consisted of four sessions of weight lifting per week, each lasting approximately $2 \frac{1}{2}$ hours. He was asymptomatic and had no past or family history of cardiac disease. Clinical examination was normal and his blood pressure was $130 / 80 \mathrm{mmHg}$.

His ECG and echocardiograph both confirmed left ventricular hypertrophy (LVH) (Figs. 1 and 2). He had voltage criteria for LVH on ECG with T-wave inversion in leads $\mathrm{V}_{4}-\mathrm{V}_{6}$ and II, III and AVF. There was an increase in left ventricular posterior wall thickness, inter-ventricular septal thickness and a dramatically increased left ventricular muscle mass (Table I). (Calculated by [(LVPW + IVS + LVIDD) $^{3}-\left(\right.$ LVIDD $\left.\left.\left.^{3}\right)\right] \times 1.05\right)$.

\section{DISCUSSION}

The use of anabolic drugs in sport is thought to be widespread. However, studies have shown conflicting findings as to their effectiveness in increasing skeletal muscle size and strength (Lamb, 1984; Freed et al, 1975).

Address for correspondence:

Dr. G. McKillop

Registrar

Cardiology Department

Victoria Infirmary

GLASGOW

G42 9TY
We were unable to find any reports of steroid induced LVH apart from a case of hypertrophic cardiomyopathy induced by high dose steroids in a 14 month old boy (Alpert, 1984), which is of doubtful relevance to this case.

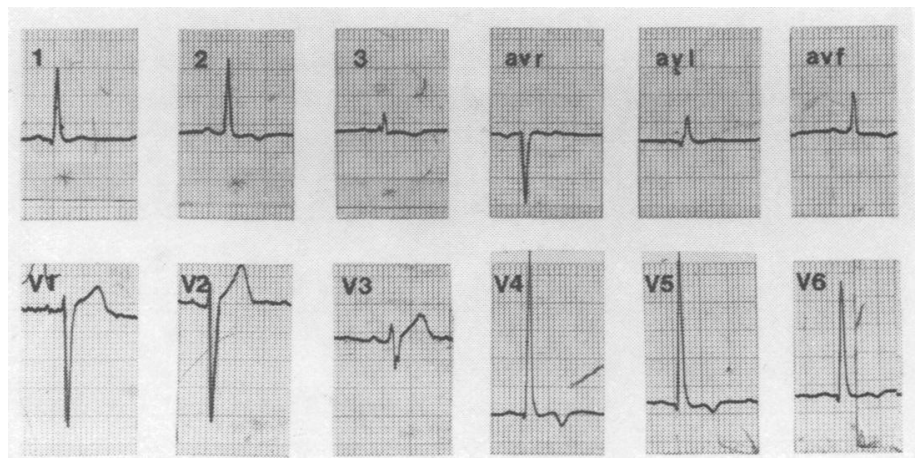

Fig. 1: 12 lead electrocardiogram showing left ventricular hypertrophy with $T$-wave inversion inferolaterally.

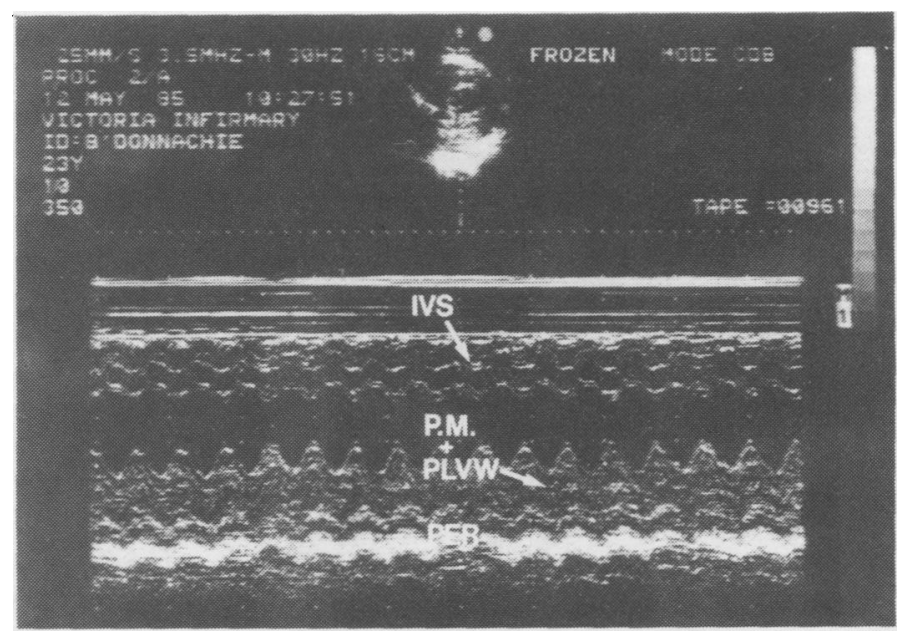

Fig. 2: M-mode echocardiogram at papillary muscle level.

An increase in left ventricular muscle thickness and mass is known to occur in athletes (Morganroth et al, 1975). However, the greatest values found in that study were left ventricular (LV) mass $348.3 \mathrm{~g}( \pm 20.8 \mathrm{~g})$, LV wall thickness $13.8 \mathrm{~mm}( \pm 0.5)$ and septum $13.5 \mathrm{~mm}( \pm 0.5)$ in world class shot putters, compared with our values of $763 \mathrm{~g}, 27 \mathrm{~mm}$ and $20 \mathrm{~mm}$ respectively. 
TABLE I

Electrocardiographic and echocardiographic measurements

\begin{tabular}{lcc}
\hline & Values & Normal Values \\
\hline ECG SV,+ RV $_{5}$ & $49 \mathrm{~mm}$ & $<36 \mathrm{~mm}$ \\
LVPWD & $2.70 \mathrm{~cm}$ & $0.6-1.1 \mathrm{~cm}^{*}$ \\
IVSD & $2.00 \mathrm{~cm}$ & $0.6-1.1 \mathrm{~cm}^{*}$ \\
LVIDD & $47 \mathrm{~mm}$ & $37-56 \mathrm{~mm}$ \\
LV Mass & $763 \mathrm{~g}$ & $180-230 \mathrm{~g}$ \\
LV Mass Index & $357 \mathrm{gm} / \mathrm{m}^{2}$ & - \\
EF & $59 \%$ & - \\
\hline
\end{tabular}

Abbreviations:

ECG SV $1+R V_{5}=$ Sum of $S$ Wave in $V_{1}$ and $R$ Wave in $V_{5}$. LVPWD = Left Ventricular Posterior Wall (diastole)

IVSD = Interventricular Septum (diastole)

LVIDD = Left Ventricular Inter Dimension Diastole

LV Mass $=$ Left Ventricular Mass

LV Mass Index = Left Ventricular Mass Per Unit Surface Area

$E F=$ Ejection Fraction by Simpson's Rule

It is possible that this subject has a cardiomyopathy, but there were no echocardiographic features of a hypertropic obstructive cardiomyopathy (HOCM) and his ejection fraction (Simpson's Rule) was normal. LV masses of this order. have been reported only in cases of severe valvular disease (Bennet and Evans, 1974), but our patient had no clinical or echocardiographic evidence of this.

We think it probable therefore that anabolic steroids augment the effects of regular physical exercise on the myocardium. We do not know the physiological or pharmacological mechanisms behind this muscle hypertrophy, but we assume that myofibrillar hypertrophy and increased intra-cellular storage products are involved. It is possible that such changes only occur in individuals taking anabolic steroids while undergoing regular training.

The long-term consequences of this degree of hypertrophy are rather worrying for two reasons. Firstly the increased muscle mass may jeopardise blood supply to the subendocardial layers in later life particularly if atherosclerosis supervenes. Secondly anabolic steroids may be implicated in the atherosclerotic process itself.

We feel that the effects of anabolic steroids on left ventricular mass may be significant and represent a hitherto unrecognised danger to those athletes abusing these drugs, and hence merits further study.

\section{References}

Alpert, B. S., 1984 "Steroid induced hypertrophic cardiomyopathy in an infant". Paediatr.Cardiol. 5: 117.

Bennet, D. H. and Evans, D. W., 1974 "Correlation of left ventricular mass determined by echocardiography with vectoro cardiographic and electrocardiographic voltage measurements". Br.Heart J. 36: 981.

Freed, D. L. J., Banks, A. J., Longson, D. and Burley, D. M., 1975 "Anabolic steroids in athletes: Cross-over double-blind trial in weightlifters". Br.Med.J. 2: 471

Lamb, D. R., 1984 "Anabolic steroids in athletes: How well do they work and how dangerous are they?" Am.J.Sports Med. 12: 31.

Morganroth, J., Mason, B. J., Henry, W. L. and Epstein, S. E., 1975 "Comparative left ventricular dimensions in trained athletes". Ann.Int.Med. 82: 521

\section{BOOK REVIEW}

Title:

ATHLETIC TRAINING AND SPORTS MEDICINE

Authors: American Academy of Orthopaedic Surgeons

Publisher: $\quad$ Churchill Livingstone, Edinburgh. 1986

Price: $f 40.00 \quad 602$ pp. with Index

ISBN 0-89203-002-X

This well presented book is stated in the preface to be 'not intended for the exclusive use of Physicians or experienced athletic trainers', this wide audience causes problems. There are parts of the book which are of value to Doctors, others to Physiotherapists and others to Coaches or Trainers, but I doubt if there is sufficient in the whole to encourage any one group to spend the required $£ 40.00$.

There is a large and useful section on examination of the knee with mention of various of the modern tests of ligament function. However, the classification of ligamentous instability which is used in the book, is the subject of continuing debate and these concepts are not often accepted in this country. The section on injuries to the ankle is also useful. They describe the Anterior Drawer Test for instability of the ankle which I have found most useful in practice because in the initial assessment it appears to cause little distress to the patient, whereas Talar Tilt can rarely be assessed adequately without local or general anaesthesia. The use of arthrography in the diagnosis of ankle injury is stressed but rarely used here.

The section on Athletic Training is of some value to Doctor or Physiotherapist with little knowledge of Sports Medicine but there are certainly many better places in which to study this topic even at a superficial level. The book contains of lot of basic anatomy, there are 47 pages on 'Taping' and there is a glossary of 31 pages explaining simple medical terms. Various medical problems are discussed including nutrition, the environment, poisonous stings and bites. There is also a section on Basic Life Support, that is to say the initial management of the severely ill or injured patient, which is useful.

Overall I think the book will find a place in a library, but I doubt if there will be many individual sales.

I. D. Adams, MD 